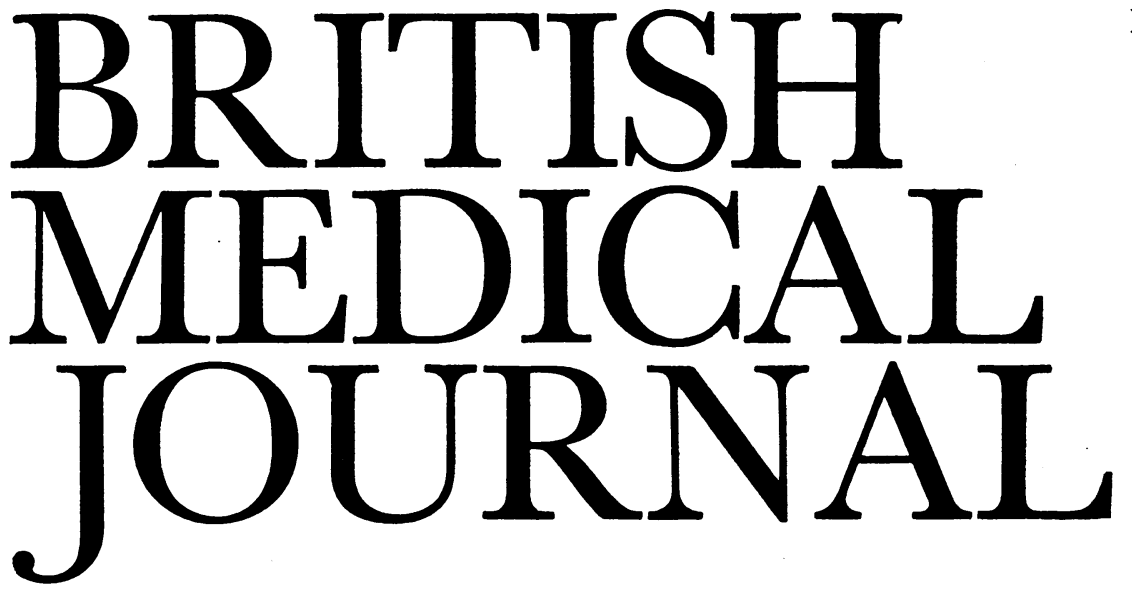

LONDON, SATURDAY 3 DECEMBER 1983

\title{
Fetal monitoring during labour
}

Is fetal monitoring worth while ? was the title of a leading article in the $B M F$ in $1971^{1}$ which concluded that continuous monitoring of the fetal heart rate and measurement of scalp pH might allow labour to be undertaken and continued in high risk pregnancy where otherwise a caesarean section would be performed. The article suggested that intrapartum monitoring might allow early detection of asphyxia and reduce the number of asphyxiated infants delivered, although it drew attention to the lack of published evidence to support this.

Since then, numerous retrospective analyses and five prospective randomised controlled trials-three in high risk ${ }^{2-4}$ and two in low risk ${ }^{6}$ pregnancy-have been published, showing that continuous monitoring of the fetal heart rate in high risk pregnancy may prevent intrapartum stillbirths and reduce neurological complications in neonates, but that this may be at the expense of an increase in the rate of caesarean section. The concurrent use of fetal scalp blood sampling may not only improve the fetal outcome but also reduce the caesarean section rate. Such benefits, however, were not apparent in the low risk pregnancies. Though these studies confirm that fetal monitoring may prevent neurological sequels, they fail to show a significant improvement overall in the condition of the fetus at birth. This suggests that, although monitoring detects severe fetal distress, it fails to detect less severe cases. In a study by Sykes et al (1 October, p 943) of selective monitoring of high risk pregnancies and those in which the fetal heart rate was abnormal on auscultation, monitoring detected fetal distress in only $16 \%$ of cases in which the infant was subsequently found to have severe acidosis and an Apgar score of less than 7 at one minute. Conversely, most of the infants who were thought to have had fetal distress were vigorous and were not severely acidotic. The authors monitored $46 \%$ of the labours, and almost half of the infants who were born with severe acidosis occurred in the supposedly low risk group who were not monitored. Failure to identify those at risk has been noted before and led to the recommendation that all labours should be monitored. ${ }^{7}$ Possibly this may be supported by a sufficiently large randomised trial, but it is probably now more important to seek to improve on current techniques than to strive to justify them, if the benefit is not immediately obvious. The need for adequate intrapartum monitoring cannot be denied, but unfortunately, objective evaluation of continuous fetal monitoring has lagged behind the widespread adoption of the technique by many obstetric units. The apparent benefit of monitoring in high risk pregnancy must be weighed against the cost of increased operative intervention and maternal morbidity, restriction of the mother during labour, and increased medical and nursing effort. On the other hand, on a purely financial basis such costs may be justified by the prevention of even a few handicapped children. ${ }^{8}$

There are various reasons why continuous monitoring of the fetal heart rate and fetal scalp sampling are insufficiently accurate to detect fetal distress: fetal heart rate patterns correlate poorly with the acid base balance, particularly when heart rate abnormalities are present ${ }^{9}$; scalp sampling is usually carried out because of abnormalities in the fetal heart rate and hence some "at risk" fetuses are missed; the relation of scalp $\mathrm{pH}$ to blood gas state is complex ${ }^{1011}$; and the ability of the fetus to withstand hypoxia and acidosis varies, being particularly dependent on glycogen stores. Fetal outcome depends not only on correct interpretation of the data but also on appropriate action by the staff in the obstetric unit. A high standard of midwifery and medical skill is required, and since this may be better than average in units carrying out trials the results so far are not particularly encouraging. Improving the staffing levels and skills in the labour ward-currently a topic of much discussion inside and outside the professionsmay benefit fetal outcome, but more reliable methods of fetal monitoring are clearly needed.

Current methods of monitoring have recently been reviewed ${ }^{12}$; there have also been attempts to simplify interpretation of the fetal heart rate trace by a simple calculation of the "dip area," 13 the use of computers to evaluate deceleration patterns ${ }^{14}$ or produce a compact description of fetal heart rate activity, ${ }^{15}$ and detailed analysis of electromechanical intervals of the fetal cardiac cycle. ${ }^{16}$ None of these methods has yet been adequately evaluated. Values of $\mathrm{Po}_{2}$ and $\mathrm{PCO}_{2}$ are important in interpreting scalp blood results, ${ }^{11}$ and the base excess is also a useful guide to the saturation of the buffering capacity. The maintenance, calibration, and size of the blood sample required by blood gas analysers have proved a problem, but an instrument with fully automatic calibration which needs only 10-15 $\mu 1$ of blood has recently become available. ${ }^{17}$ Continuous scalp $\mathrm{pH}$ and $\mathrm{Po}_{2}$ recordings have proved useful in research studies but such recordings are not available in most units. Additional biochemical data 
on scalp blood, such as measurement of lactate concentration, do not appear to improve diagnostic accuracy. Results of direct intrapartum monitoring of the neurological state of the fetus by electroencephalogram recordings ${ }^{1819}$ are difficult to interpret and once again probably identify only severe fetal distress.

Against a background of slow technical progress there has been an increasing demand for more "natural" labour. Mothers often accept fetal monitoring, ${ }^{20}$ especially when they have had previous obstetric problems. Radiotelemetry ${ }^{21}$ allows more mobility and although this may not confer any great obstetric advantage, ${ }^{22}$ it should make fetal heart rate monitoring more acceptable and it is surprising that it has not had a more enthusiastic reception.

There is not, and is never likely to be, a single simple test of fetal wellbeing in labour. It is impossible to predict with sufficient accuracy which fetuses will become distressed, and probably all labours should be monitored. At present this entails fetal heart rate recording and scalp blood analysis, for the evidence suggests that if continuous monitoring of the fetal heart rate is used scalp blood analysis is an essential adjunct. Far more attention should be given to analysis of fetal heart rate traces by computer, since if this is shown to be beneficial inexpensive microprocessors could be used on a wide scale. It is high time that we had a new generation of smaller and more intelligent fetal heart rate monitors which, together with telemetry might make fetal monitoring in labour more effective and less intrusive.

\section{ROBERT S SAWERS}

Senior Lecturer and Consultant Obstetrician and Gynaecologist, Birmingham Maternity Hospital

Birmingham B15 2TG

1 Anonymous. Is fetal monitoring worthwhile? $\mathrm{Br} \mathrm{Med} \mathcal{F} 1971$; :515-6.

${ }^{2}$ Haverkamp AD, Thompson $\mathrm{HE}, \mathrm{McFee} \mathrm{JG}$, Cetrulo C. The evaluation of continuous fetal heart rate monitoring in high-risk pregnancy. $A m \mathcal{F}$ Obstet Gynecol 1976;125:310-20.

${ }^{3}$ Renou P, Chang A, Anderson I, Wood C. Controlled trial of fetal intensive care. Am $\mathcal{F}$ Obstet Gynecol 1976;126:470-6.

4 Haverkamp AD, Orleans M, Langendoerfer S, McFee J, Murphy J, Thompson HE. A controlled trial of the differential effects of intrapartum fetal monitoring. Am $\mathcal{F}$ Obstet Gynecol 1979;134:399-412.

5 Kelso IM, Parsons RJ, Lawrence GF, Aroroa SS, Edmonds DK, Cooke ID. An assessment of continuous fetal heart rate monitoring in labor. A randomized trial. Am $\mathcal{F}$ Obstet Gynecol 1978;131:526-32.

6 Wood C, Renou P, Oats J, Farrell E, Beischer N, Anderson I. A controlled trial of fetal heart rate monitoring in a low-risk obstetric population. Am F Obstet Gynecol 1981;141:527-34.

${ }^{7}$ Edington PT, Sibanda J, Beard RW. Influence on clinical practice of routine intra-partum fetal monitoring. $\mathrm{Br} \mathrm{Med} \mathcal{F} 1975$;iii:341-3.

${ }^{8}$ Quilligan EJ, Paul RH. Fetal monitoring: is it worth it? Obstet Gynecol $1975 ; 45: 96-100$

${ }^{9}$ Beard RW, Filshie GM, Knight CA, Roberts GM. The significance of the changes in the continuous fetal heart rate in the first stage of labour. Fournal of Obstetrics and Gynaecology of the British Commonwealth $1971 ; 78: 865-81$.

10 Pearson JF. Maternal and fetal acid-base balance. In: Beard RW, Nathanielsz PW, eds. Fetal physiology and medicine. London: W B Saunders, 1976:492-509.

11 Wood EC. Scalp sampling, amnioscopy. In: Gluck L, ed. Intrauterine asphyxia and the developing fetal brain. London: Year Book Medical Publishers Inc, 1977:179-90.

12 Pearce JM, Willson K. Fetal heart rate monitors-some clinical and technical aspects. Br 7 Hosp Med 1983;30:123-31.

${ }^{13}$ Shelley T, Tipton RH. Dip area. A quantitative measure of fetal heart rate patterns. Fournal of Obstetrics and Gynaecology of the British Commonwealth $1971 ; 78: 694-701$.

14 Beguin F, Yeh SY, Forsythe A, Hon EH. A study of fetal heart rate deceleration areas. II. Correlation between deceleration areas and fetal pH during labor. Obstet Gynecol 1975;45:292-8.

15 Henry MJ, McColl DDF, Crawford JW, Patel N. Computing techniques for intrapartum physiological data reduction. II. Fetal heart rate. f Perinat Med 1979;7:215-28.

16 Hon EH, Koh KS. Electromechanical intervals of the fetal cardiac cycle. Clin Obstet Gynaecol 1979;6:215-21.

17 Stewart P, Hillan E, Calder AA, Nicol SM. A comparative assessment of an automated blood microprocessor for fetal blood $\mathrm{pH}$ measurements in the labour ward. Br 7 Obstet Gynaecol 1983;90:522-4.
18 Wilson PC, Levy LF, Spies S, Chadwicke J. The technique of fetal electroencephalography during labour. Br 7 Obstet Gynaecol 1979;86:266-8.

9 Maynard DE, Cigen RJ, Viniker DA. Intrapartum fetal monitoring with the cerebral function monitor. Br $\mathcal{F}$ Obstet Gynaecol 1979;86:941-7.

${ }^{20}$ Molfese V, Sunshine P, Bennett A. Reactions of women to intrapartum fetal monitoring. Obstet Gynecol 1982;59:705-9.

21 Flynn AM, Kelly J, Hollins G, Lynch PF. Ambulation in labour. Br Med $\mathcal{F}$ 1978 ;ii:591-3.

${ }^{22}$ Haukkamaa $M$, Purhonen M, Teramo $K$. The monitoring of labor by telemetry. F Perinat Med 1982;10:17-22.

\section{Changing attitudes to exercise induced asthma}

Bronchoconstriction induced by exercise is a common feature in patients with both allergic and non-allergic asthma. In asthmatic children this symptom may be particularly troublesome and may lead to physical and emotional isolation by their peer groups. Over the past few years growing medical awareness of the problems associated with exercise induced asthma has led to changing attitudes and has encouraged investigation into its mechanism so that a more rational approach may be applied to its management.

The precipitating event in exercise induced bronchoconstriction is cooling of the airway mucosa during humidification of the inspired air. ${ }^{1}$ In the laboratory this can be measured as respiratory heat exchange and depends on the rate and depth of ventilation ${ }^{2}$ and the temperature and humidity of the inspired air. ${ }^{3}$ Exercise in a warm, humid atmosphere produces less bronchoconstriction than the same exercise performed under cold, dry conditions ${ }^{4}$ - which explains (in part) why exercise induced asthma occurs more frequently in runners than in swimmers doing the same amount of work.

By itself exercise serves only to increase the tidal volume and respiratory frequency and is not essential to the bronchoconstriction. Indeed, sedentary hyperventilation under isocapnic conditions can induce the same degree of bronchoconstriction as with exercise provided the two stimuli are matched for respiratory heat exchange. ${ }^{56}$ Whether cooling of the airways or loss of water from the bronchial mucosa is the primary stimulus for bronchoconstriction has to be elucidated. Nor is it certain how a thermal stimulus to the large airways is propagated to the smaller airways during exercise induced bronchoconstriction. The close correlation between the ability of exercise or isocapnic hyperventilation to produce bronchoconstriction and the response of the airways to nonspecific bronchial provocants such as methacholine or hista- $N$ mine suggests that exercise induced asthma is a reflection of $D$ non-specific bronchial hyperreactivity. ${ }^{7}$

Several theories have been put forward to link airway reactivity with exercise induced asthma. One such mechanism, which may be loosely defined as the "leaky mast cell theory," is that increased local concentrations of inflammatory mediators $c$ in the airways may alter the threshold at which the smooth muscle or sensory nerves respond to a fall in temperature. ${ }^{8}$ Alternatively a reduction in the temperature or changes in the hydration of the bronchial mucosa may stimulate release of inflammatory mediators. ${ }^{9}$ After exercise plasma values of a high molecular weight neutrophil chemotactic activity and histamine both rise, ${ }^{10}$ two mediators which are associated with mast cells. Furthermore, the mast cell stabilising drug sodium cromoglycate inhibits both the mediator and airway responses to exercise. ${ }^{11}$ These observations should, however, be interpreted with some caution since there is no definitive evidence 